\title{
Jessner lymphocytic infiltration of the skin
}

INSERM

\section{Source}

INSERM. (1999). Orphanet: an online rare disease and orphan drug data base. Jessner lymphocytic infiltration of the skin. ORPHA:33314

Jessner lymphocytic infiltration of the skin (ULIS) is a chronic benign cutaneous disease characterized by asymptomatic non-scaly erythematous papules or plaques on the face and neck. 